\title{
FORMAÇÃO DE PROFESSORES E O ENSINO DE LEITURA CRÍTICA DE GÊNEROS
}

\author{
Marcia Juliana Dias de Aguiar \\ amysunbr@yahoo.com.br
}

\section{RESUMO}

Ao se considerar o contexto de ensino, é relevante prestar atenção ao modo pelo qual os professores desenvolvem suas aulas. De fato, as aulas são uma conseqüência do modo como eles concebem as teorias de ensino e aplicam-nas em sala de aula. $O$ objetivo deste estudo é fornecer uma visão simplificada sobre a pesquisa-ação e o processo de formação dos professores. Além disso, faz-se necessário enfatizar o uso de gêneros no ambiente de sala de aula, baseando-se numa perspectiva crítica de análise.

\section{INTRODUÇÃO}

Considerando a necessidade sempre imperiosa de atualização e especialização dos professores em relação às suas práticas de ensino, é necessário fornecer meios para professores e alunos-professores melhorarem suas abordagens de ensino. Este artigo tem como objetivo apresentar as relações da pesquisa-ação com a formação de professores críticos, bem como examinar a possibilidade de proporcionar um ensino de leitura crítica a partir do trabalho com gêneros.

Nesse sentido, é clara a importância de se oferecer aos acadêmicos meios para que eles investiguem suas próprias práticas e melhor possam desempenhar o seu papel de professor. Suas práticas precisam estar associadas à pesquisa, auto-observação e ação, a fim de provocar mudanças em seu modo de agir em sala de aula, possibilitando resultados eficazes de aprendizagem.

Cristóvão (2002:38) enfatiza que refletir sobre o processo de ensino possibilita o aperfeiçoamento do professor a partir do momento que através de mudanças significativas se moldam novas abordagens para o ensino. 
Nessa perspectiva, a metodologia de pesquisa-ação fornece instrumentalização para o desenvolvimento de professores que realmente desejam se engajar no processo avaliativo e construtivo realizado pelo professor na pesquisa-ação, e alinha-se paralelamente à utilização de gêneros no ensino de leitura em espaços que possibilitem o crescimento do professor em formação.

\section{PESQUISA-AÇÃO E A FORMAÇÃO DE PROFESSORES}

$\mathrm{Na}$ busca por um ensino de língua estrangeira de qualidade e eficiente, faz-se necessário um trabalho árduo e contínuo em relação à preparação de professores. Um professor munido com todas as ferramentas e conhecimento que possam oferecer ao aluno um processo de aprendizagem significativo é o grande objetivo que permeia todos aqueles envolvidos no contexto de ensino. Para tanto, é relevante que professores e acadêmicos de Letras trabalhem a profissionalização docente, baseando-se em teorias e métodos práticos para a melhoria do ensino de LE.

Desse modo, processos de investigação em sala de aula, através de uma parceria colaborativa entre pesquisadores e acadêmicos em formação são de extrema relevância para se verificar os problemas existentes e, assim, solucioná-los. Somente uma análise crítica do contexto real de ensino propiciará os obstáculos existentes no processo educativo enfrentado por professores e alunos, fazendo com que a ação engajada em pesquisa e prática possa solucionar esses problemas.

Richter (2000: 83) comenta:

\footnotetext{
Percebe-se, então, que a aprendizagem de uma língua e a ação social que constrói e transforma o homem e o mundo são inseparáveis. Ação social que requer uma nova visão do que é educar: emancipar, levar o educando à autonomia cooperativa. Essa forma de educar é conquistada na medida em que tanto professor quanto aluno se tornam (também) investigadores de seu próprio procedimento.
}

Além de observar os problemas na sala de aula, é necessário que professores e/ou alunos-professores reflitam sobre suas ações e maneiras de ensinar, pois com base nesta ação-reflexão será possível encontrar os melhores métodos de ensino, bem como ajuda na construção clara do perfil do professor, seu papel e função. 
Burns (1999:16) acredita que a pesquisa-ação colaborativa seja uma importante abordagem para o desenvolvimento e aprimoramento de professores e professores em formação, além de proporcionar ferramentas para a melhoria do ensino em ambientes educativos e crescimento profissional do professor.

... investigação em sala de aula e auto-reflexão são componentes importantes do crescimento profissional, fornecendo uma fonte sólida para o planejamento e ação pedagógica e permite estruturar as decisões locais da sala de aula dentro de considerações educacionais, institucionais e teóricas mais amplas. ${ }^{1}$

De acordo com Burns (1999:31) a pesquisa-ação é um processo estruturado de investigação de questões e/ou preocupações práticas dentro de um contexto específico. Para isso é apropriada a colaboração de participantes que juntos buscarão respostas para perguntas situacionais, que evidenciarão possibilidades de mudança.

Em contraste, para algumas outras formas de pesquisa, as quais procuram testar idéias teóricas e validá-las independentemente, a pesquisa-ação é dirigida por ações práticas das quais teorias sobre aprendizagem e ensino podem ser traçadas. ${ }^{2}$

Basicamente, a pesquisa ação vai ser desenvolvida pela coleta de dados que abrirão portas para o processo de ensino e aprendizagem dos membros envolvidos nesta ação. Considerando a metodologia de pesquisa-ação, tem-se que, devido ao fato de ela ser focalizada em áreas práticas inseridas em contextos específicos, os modos de pesquisa apresentam-se bastante flexíveis.

Contudo, Burns propõe 11 fases que podem ser vistas na pesquisa ação e que podem intercalar-se de acordo com as necessidades e propriedades de cada ambiente escolar. A autora (idem:35) apresenta a seqüência de fases que refletem os tipos de questões significativas para professores ao longo da pesquisa.

\footnotetext{
${ }^{1}$ A tradução é de responsabilidade da autora: "classroom enquiry and self-reflection are important components of professional growth, providing a sound source for pedagogical planning and action and enabling them to frame the local decisions of the classroom within broader educational, institutional and theoretical considerations."

2 "In contrast, to some other forms of research which seek to test out theoretical ideas and to validate them independently, action research is driven by practical actions from which theories about learning and teaching can be drawn."
} 
a) Exploring (Exploração): Relaciona-se à identificação e acordo sobre o aspecto de interesse do grupo. É a origem da ação, em que a documentação, observação sobre o problema é clarificado.

b) Identifying (Identificação): Refere-se ao processo de descoberta de um fato, o qual possibilita para os membros da pesquisa uma certa clareza de idéias sobre o foco de estudo com vistas para preparação de mais investigações estruturadas.

c) Planning (Planejamento): Este item representa o desenvolvimento de planos de ação para obtenção de dados, bem como buscar métodos de pesquisa adequados.

d) Collecting data (Coleta de dados): Representa o período de coleta de dados e seus procedimentos de seleção.

e) Analysing/Reflecting (Análise/Reflexão): Possibilita a análise e reflexão detalhada dos dados coletados; isto ocorre através de um processo organizado de análise e interpretação.

f) Hypothesising/Speculating (Hipotetizar/Especular): A principal função é lançar hipóteses sobre o que seria provável de acontecer em função de uma determinada situação.

g) Intervening (Intervenção): Corresponde às mudanças práticas como conseqüências das análises feitas.

h) Observing (Observação): Análise dos resultados obtidos através da intervenção, bem como sua eficiência.

i) Reporting (Relatar): Relato dos processos e resultados da pesquisa para o grupo de pesquisa.

j) Writing (Redigir): Redação em um artigo, relatório, os processos e fases da pesquisa.

k) Presenting (Apresentação): Apresentação e divulgação da pesquisa para públicos mais amplos.

Acredita-se que através dessa estrutura básica de pesquisa seja possível ao professor organizar-se melhor em busca de um aperfeiçoamento do ensino. É evidente que a pesquisa-ação segue uma linha em que as fases podem ocorrer simultaneamente, ou, até mesmo, em ordem diferenciada. A simultaneidade das fases é possível, pois cada pesquisa é adaptada às circunstâncias específicas, e aos seus participantes. 
No que diz respeito aos benefícios da pesquisa ação, observa-se que professores tendem a tornar-se pesquisadores e teoristas sobre suas próprias práticas de ensino. Eles transformam-se em professores dinâmicos, ativos e engajados profundamente no processo escolar, que, certamente, será modificado ou reestruturado depois de submetido à metodologia de pesquisa-ação. Eles gradativamente devem adquirir olhos críticos para todo e qualquer problema, nunca sendo passivos e/ou submissos diante das armadilhas tradicionais do ambiente de ensino. A noção de reflexão, ação, mudança e melhoramento aparece automaticamente ligada ao professorpesquisador, pois, a partir do momento que professores e/ou professores em formação realmente buscarem o melhor para sua sala de aula, enfrentando medos e normas inadequadas e arcaicas, os benefícios para os alunos em termos de aprendizagem para a vida serão evidentes.

Para concluir, os professores devem ter a iniciativa de buscar melhorias nos seus modos de ensinar e a PA concretiza-se numa forma de crescimento profissional que visa uma ação transformadora ancorada na solução de um possível problema em uma dada situação social. Thiollent (1996:8), ao atribuir o objetivo geral da pesquisa ação, menciona a seguinte declaração, que reafirma o que foi anteriormente demonstrado:

\footnotetext{
Um dos principais objetivos dessas propostas consiste em dar aos pesquisadores e grupos de participantes os meios de se tornarem capazes de responder com maior eficiência aos problemas da situação em que vivem, em particular sob forma de diretrizes de ação transformadora.
}

\section{OS GÊNEROS E A INSTRUMENTALIZAÇÃO DO PROFESSOR EM SALA DE} AULA

Com o intuito de formar professores cientes de suas práticas e reflexivos, professores em formação devem comprometer-se a pesquisar e auto-observar seu desempenho em sala de aula, sempre tentando melhorar, enriquecer a sua abordagem para o ensinar e aprender. Na procura por mudanças significativas e viáveis, tenta-se "centralizar", atualmente, o ensino para um uso qualitativo de gêneros. 
Para que o professor possa proporcionar ao seu aluno uma leitura crítica do mundo, das coisas, dos textos, é necessário que ele procure conhecer profundamente teorias que o permitam trabalhar de forma adequada com gêneros.

Para isso, professores precisam adotar uma concepção de gênero e a partir dela delinear meios de como introduzi-lo adequadamente em sala de aula. Definições de gêneros que os concebem como ação social, como manifestação do discurso nas mais diversas práticas sociais do homem, são as que melhor proporcionariam uma análise mais completa no que diz respeito à relação texto, discurso, contexto e estrutura social.

A relação dos gêneros com suas respectivas situações comunicativas apresenta-se de extrema importância para o contexto de ensino, principalmente, por que envolve um contexto específico, no qual se verifica uma dada situação concretizada por indivíduos que constituem e representam o discurso. Sendo assim, o gênero constituise em uma ferramenta de aquisição de conhecimento discursivo para professores e alunos em sala de aula.

Para Bakhtin (1997:279), a língua é utilizada através de enunciados orais e escritos por interlocutores dentro de uma situação específica da atividade humana:

\begin{abstract}
O enunciado reflete as condições específicas e as finalidades de cada uma dessas esferas, não só por seu conteúdo (temático) e por seu estilo verbal, ou seja, pela seleção operada nos recursos da língua - recursos lexicais, fraseológicos e gramaticais - mas também, e sobretudo, por sua construção composicional.
\end{abstract}

Considerando essa declaração, tem-se condições de estabelecer a definição de gênero, segundo o ponto de vista bakhtiniano (1997:283-4) como cada representação tipológica estruturada de enunciados que se associa, relaciona diretamente a situações comunicativas específicas. O seguinte esquema representa simplificadamente a idéia de gêneros de Bakhtin: 


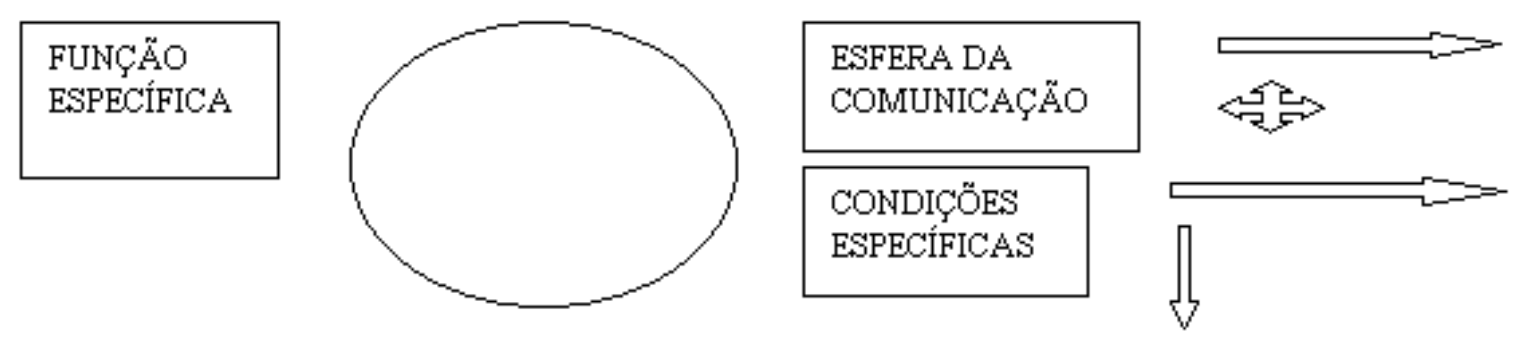

Gênero: um tipo de enunciado com relação estável do conteúdo temático + estilo +construção composicional

Dessa forma, Bakhtin esclarece a noção de gênero por demonstrar que o estilo lingüístico ou funcional vem a ser o estilo de um gênero peculiar a uma determinada esfera da atividade e da comunicação humana.

É visível a importância dos gêneros como objeto de ensino/aprendizagem, pois eles representam esquemas lingüístico-textuais e organizacionais estáveis que se associam a domínios discursivos específicos. De acordo com essa argumentação, Koch (2002:55)

Entende o domínio (maestria) do gênero como o próprio domínio da situação comunicativa, domínio este que se pode dar através do ensino das capacidades de linguagem, isto é, pelo ensino das aptidões exigidas para a produção de um gênero determinado.

Com essa visão, pensa-se que ensinar, utilizando como material didático gêneros, constitui-se em algo significativo, desde que bem detalhado na materialidade textual e sempre contextualizado nas práticas sociais. Mas para isso o professor em formação precisa aprender como lidar com esses gêneros, através da aquisição de estratégias de leitura crítica, as quais proporcionariam um percurso seguro a ser seguido ao trabalhar-se com gêneros.

Além disso, o trabalho com gêneros é de fundamental importância, pois constitui-se em uma forma de desenvolver no aluno suas capacidades de ação, discursivas e lingüístico discursivas, bem como as psicolingüísticas; Koch (2002:56) menciona a hipótese de Schneuwly \& Dolz de que:...é através dos gêneros que essas práticas se 
“encarnam' nas atividades de aprendizagem, justamente em virtude de seu caráter intermediário e integrador.

Partindo desses pressupostos, pode-se perceber o quão importante é para o professor em formação a ciência dessas relações dos gêneros (sujeito- ação- instrumento de ensino) (Schneuwly,1994 apud Koch 2002) para que o mesmo possa se aperfeiçoar e assim ter condições de trabalhar qualitativamente gêneros em sala de aula. Finalizando, o que Koch (op.cit.:55) diz a respeito da relação formação de professor e gênero é realmente relevante para o crescimento profissional do professor:

\begin{abstract}
O ensino de gêneros seria, pois, uma forma concreta de dar poder de atuação aos educadores e, por decorrência, aos seus educandos. Isto porque a maestria textual requer- muito mais do que os outros tipos de maestria- a intervenção ativa de formadores e o desenvolvimento de uma didática específica.
\end{abstract}

\title{
4. ENSINO DE LEITURA CRÍTICA
}

Levando em consideração os aspectos previamente mencionados sobre a formação de professores e o uso de gêneros como instrumento de análise como material didático, abre-se um espaço para conceber a importância do processo de leitura crítica no ensino de língua estrangeira. Mas no que se constituiria uma leitura crítica? Em linhas gerais, ler criticamente poderia ser classificado através de uma exploração profunda do texto em seus aspectos materiais, semânticos, bem como captar, o mais adequadamente possível, as inferências tacitamente estabelecidas no texto pelo escritor. Ler criticamente seria o que Wallace (1996:59) apresenta como "reading between the lines", ler nas entrelinhas.

Explicitando essa declaração, é apropriado realçar que para Wallace (1996:61) ter uma visão crítica de um texto é revelar, em maior ou menor grau, as ideologias que mantêm as relações sociais e diferenças de poder vigentes na organização da nossa comunidade, as quais podem ser vistas em muitos textos contemporâneos.

Em geral, eu quero argumentar que uma leitura efetiva envolve o desafio de assunções ideológicas, bem como o conhecimento proposicional em textos escritos, e que nós como professores podemos Ter a necessidade de guiar 
leitores a uma consciência do conteúdo ideológico simplesmente por que é tão freqüentemente apresentado como 'óbvio'. ${ }^{3}$

Essa idéia relaciona-se ao conceito de análise crítica do discurso de Fairclough (1989) em que a análise textual não se restringe apenas aos aspectos lingüísticos, mas os relaciona com a estrutura social, contexto e discurso, buscando desvendar crenças, valores, ideologias, relações de poder nos textos em função de uma situação comunicativa e discurso específicos.

Desse modo, desmascarar este senso comum, destruir esta passividade de alguns leitores diante do 'óbvio' e dos imutáveis mitos sociais representados por diversas formas em gêneros textuais específicos, constituem-se em objetivos claros de uma leitura crítica segundo Wallace. Além disso, três aspectos podem guiar, de uma forma abrangente, os caminhos do professor no processo de leitura. Primeiro, a necessidade de se estabelecer uma relação das atividades de leitura, e também seus textos escritos com o contexto no qual estão inseridos. Segundo, buscar textos que provoquem o aluno, instiguem a reflexão e a revelação de subentendidos/ aspectos inferenciais. Terceiro, a procura por uma estratégia metodológica para interpretação de textos ideologicamente preenchidos e com significado proposicional.

Segundo Richter (2000:83) existem estratégias de leitura que possibilitam o reconhecimento das relações entre aspectos gramaticais e semânticos dentro do texto e por isso devem ser utilizados. Por exemplo, inferências podem ser explicitadas pelo processo de "acoplamento" ao texto de trechos que podem ser facilmente deduzidos em função do contexto textual.

Na concepção de Motta-Roth (1998:7), o ensino de leitura deve ser voltado para a comunicação, ou seja, um diálogo entre o escritor e leitor através do texto. Nesse processo, através da linguagem, o leitor torna-se ciente das idéias do escritor, construindo sentidos a partir de seu conhecimento enciclopédico, aceitando, criticando, duvidando, complementando os preceitos do escritor. Assim, o texto deve

\footnotetext{
3 Tradução da autora: "Generally, I want to argue that effective reading involves challenging the ideological assumptions as well as propositional knowledge in written texts and that we as teachers may need to guide readers to an awareness of ideological content simply because it is so often presented as 'obvious'."
} 
servir como um mediador entre o leitor e o escritor, sendo que o leitor é que constrói a significação do texto baseando-se nas informações textuais e seu conhecimento de mundo.

O texto então passa a ser visto como linguagem materializada em uma unidade de significado, utilizada em um contexto, com um dado objetivo, materializando discursos e, assim refletindo uma determinada visão do mundo.

Nunan (1989:33) manifesta da mesma opinião sobre o processo interativo de leitura ao dizer que:

... ler é um processo interativo entre o que o leitor já sabe sobre um dado tópico ou matéria e o que o escritor escreve...Bons leitores são capazes de relacionar o texto e o seu conhecimento de mundo eficientemente. ${ }^{4}$

Para o mesmo autor (op.cit:50), o processo de leitura envolve um reconhecimento por parte do professor dos propósitos de leitura associados às habilidades necessárias para isso. Sendo assim, deve-se desenvolver as mais variadas habilidades de leitura através dos mais variados tipos de textos da nossa vida cotidiana, sempre dando relevância ao propósito de leitura.

\begin{abstract}
...um programa de leitura pode ser projetado para fornecer aos aprendizes habilidades para realizar as cento e uma tarefas de leitura que ocorrem na vida diária, ...Por outro lado, deve ser projetada para desenvolver as habilidades especializadas de leitura necessitadas para estudar com sucesso em uma Segunda língua. ${ }^{5}$
\end{abstract}

Nessa abordagem, o ensino de leitura em uma perspectiva comunicativa advogaria estratégias que possibilitassem ao cidadão leitor construir, avaliar, negociar as visões e idéias do mundo a partir da interação com o texto. É muito importante enfatizar que interação pressupõe reflexão, criticidade diante do texto, considerando seus elementos internos e externos.

\footnotetext{
${ }^{4}$ Tradução da autora: " ...reading is an interactive process between what a reader already knows about a given topic or subject and what the writer writes... Good readers are able to relate the text and their own background knowledge efficiently."

5 Tradução da autora:" ... a reading programme can be designed to provide learners with skills to carry out the hundred and one reading tasks that occur in dayly life; ... On the other hand, it might be designed to develop the specialised reading skills needed for studying successfully in a second language."
} 
Para efetivar essa intenção são necessários meios que guiem professores, e também os alunos, no processo de leitura. Por exemplo, é indispensável o reconhecimento do objeto do sentido do texto, pois ele possibilitará o entendimento pelo aluno da idéia central do texto. Um segundo ponto é a verificação do intuito do autor ao escrever o texto, quais suas intenções, o que ele pretende dizer, são aspectos que jamais podem ser esquecidos por um leitor crítico. O terceiro aspecto refere-se às formas de estruturação textual recorrentes em determinados tipos de textos (Motta-Roth 1998:12). Detalhar os modos que a linguagem se organiza em dados gêneros, bem como explorar as características visuais, discursivas e textuais dos textos representam uma estrutura de análise possível de ser usada nos ambientes de ensino de LE.

Motta-Roth (1998:28) apresenta o modelo de análise pré-pedagógica de textos de Moirand (1989) que pode ser utilizado por professores, objetivando um detalhamento dos aspectos textuais e de significação para posterior transferência aos alunos. Esse modelo baseia-se em três linhas de abordagem; a abordagem sóciolingüística, lingüística e lógico-sintática.

\begin{abstract}
A primeira é de ordem sócio-lingüística. Trata-se do levantamento das marcas enunciativas...A segunda abordagem é de ordem lingüística: procede-se ao levantamento das marcas formais da enunciação, as funções da linguagem, as modalidades apreciativas/lógicas e os atos de fala que o texto põe em evidência. Finalmente, na abordagem lógico-sintática, teremos o levantamento dos elementos icônicos, temáticos, retóricos e lógicos, bem como das relações temporais que se estabelecem no interior do texto.
\end{abstract}

Adotando uma metodologia de sala de aula que encoraja uma leitura crítica, tem-se os procedimentos de 'pre/while/post-reading' de Wallace (1996:71). No momento de 'pre-reading' as opiniões do aluno sobre o texto são verificadas. 'While-reading' proporciona um espaço para se deduzir aspectos que podem ser apresentados no texto, baseando-se em uma primeira análise geral da estrutura, título, subtítulos, imagens, tipo de texto, autor. No que diz respeito ao processo de 'post-reading' cabe enfatizar o modo pelo qual o texto poderia ser (re)escrito. É buscar na mente do aluno formas de reconstruir o texto sob uma outra perspectiva.

Além dessas três abordagens, Wallace acredita que as 5 perguntas propostas por Kress (1989) ajudam a iniciar uma leitura crítica em sala de aula. 
(1) Why is this topic being written about?

(2) How is the topic being written about?

(3) What other ways of writing about the topic are there?

(4) Who is writing to whom?

(5) What is the topic?

De uma forma simplificada, pensa-se que uma maneira de se formatar uma abordagem de leitura seja, primeiramente, um esforço concreto do professor, na medida em que ele buscará textos de interesse dos alunos, que se apresentem relevantes para aprendizagem de língua e valores sociais. Logo após, o professor pode, a partir da abordagem de Moirand (1989), verificar aspectos sócio-lingüísticos, lingüísticos e sintáticos, estabelecendo um cronograma de pontos relevantes no texto a ser explorado.

No contexto de sala de aula, antes da visualização e leitura completa do texto, o professor deve explorar seus aspectos visuais, o hipertexto presente, bem como questionar os alunos sobre idéias passíveis de se encontrar no texto em função do título, por exemplo. A opinião dos alunos em relação à relevância do tópico, a partir da análise do título, pode ser feita considerando a questão (1) de Kress, no intuito de pressupor o texto e suas razões, para futura verificação.

Após a leitura, os alunos já estão aptos a responderem às questões 2, 4 e 5 de Kress, além de, através de um trabalho conjunto com a professora, chegarem ao tipo de discurso veiculado, às representações, aos valores do escritor, e também aos participantes envolvidos e à relação de poder entre eles. Na verdade, verificar-se-ia quais as marcas lingüísticas que representam essas relações.

Na seqüência, podem ser focalizados aspectos semânticos, lingüísticos e pragmáticos relevantes para os alunos do texto. Seguindo a proposta de "post-reading" de Wallace, pode-se trabalhar com as "variáveis" do texto, ou seja, de que maneira se poderia retratar esse mesmo tópico através de uma notícia, publicidade, poesia, crônica, eqüivalendo à terceira questão de Kress. 
Para Nunan (1989:59), as atividades realizadas em sala de aula são importantes, pois elas demonstrarão como os alunos estão trabalhando com "input" adquirido. Nesse sentido, elas devem seguir três propósitos básicos para incentivar um ensino para o real uso da linguagem. As atividades devem ser um "ensaio para o mundo real", para desenvolver os "usos das habilidades" e a "fluência" e "precisão".

Nunan (idem:59) apresenta os pensamentos de Clarke e Silberstein (1977) sobre a necessidade de atividades em que o aluno utilize a língua de forma eficiente e possa lidar bem com os propósitos e abordagens das atividades de leitura.

\begin{abstract}
Atividades de sala de aula devem equiparar-se ao mundo real tão rigorosamente quanto possível. Visto que a língua é uma ferramenta de comunicação, métodos e materiais devem se concentrar na mensagem, não no meio. Além disso, os propósitos de leitura devem ser os mesmos em aula como são na vida real: 1) obter um fato específico ou pedaço de informação (escanear) 2) obter a idéia geral do autor (ler superficialmente) 3) obter um entendimento compreensivo de uma leitura, como ao ler um livro didático (através da compreensão0, ou 4) avaliar informação a fim de determinar onde se encaixa dentro do próprio sistema de crenças do indivíduo (leitura crítica). Nossos estudantes devem tornar-se tão críticos quanto nós somos dos propósitos de leitura, de modo que eles serão capazes de determinar as abordagens apropriadas a uma tarefa de leitura. ${ }^{6}$
\end{abstract}

Além disso, em uma perspectiva mais abrangente, ler criticamente confere ao leitor uma visão do discurso, no qual um dado gênero está inserido. Analisar o discurso faz com que pensemos nos valores, crenças e concepções de mundo do escritor, bem como o tipo de relacionamento estabelecido entre os participantes reportados no texto. Perceber as relações entre a estrutura social, o discurso e o texto são pontos relevantes e necessários para análise textual.

Acredita-se que fornecendo uma teoria de leitura clara e de qualidade para professores em formação seja o melhor caminho para se produzir leitores críticos em sala de aula. Fornecer os instrumentos para professores atuarem de forma produtiva

\footnotetext{
${ }^{6}$ Tradução da autora: "Classroom activities should parallel the 'real world' as closely as possible. Since language is a tool of communication, methods and materials should concentrate on the message, not the medium. In addition, the purposes of readind should be the same in class as they are in real life: 1 ) to obtain a specific fact or piece of information (scanning) 2) to obtain the general idea of the author (skimming) 3) to obtain a comprehensive understanding of a reading, as in reading a textbook (through comprehension), or 4) to evaluate information in order to determine where it fits into one's own system of beliefs 9critical reading). Our students should become as critical as we are of the purposes for reading, so that they will be able to determine the proper approaches to a reading task".
} 
no ambiente de aula é um dos grandes desafios no processo de educação e mais do que isso é fazer com que este professor, ciente de seu papel e função, opere da melhor maneira possível diante de contextos e alunos distintos, sabendo aproveitar os recursos oferecidos e/ou saber contornar a ausência deles.

\section{CONCLUSÃO}

Em suma, reunir os princípios da pesquisa-ação com a teoria de gêneros e de leitura crítica do discurso pode viabilizar uma maneira eficiente de ensinar e aprender. Mas, para isso, é necessário um processo gradativo de aprimoramento teórico e prático de professores interessados em mudar e, principalmente, formar cidadãos e não simplesmente sujeitos passivos diante das mais variadas práticas sociais.

\section{BIBLIOGRAFIA}

BAKHTIN, Mikail. Estética da Criação Verbal. São Paulo: Martins Fontes, 1997.

BURNS, Anne. Collaborative Action Research for english Language

Teachers. Cambridge University Press, 1999.

CRISTÓVÃO,V.L.L. Modelo didático de gênero como instrumento para

formação de professores. In J.L. Meurer, D. Motta-roth (orgs.): Gêneros textuais. Bauru, SP: EDUSC,2002

KOCH, I.G.V. Desvendando os segredos do texto. São Paulo: Cortez,2002

MOTTA-ROTH, Désirée. Leitura em Língua Estrangeira na escola. Santa Maria: UFSM, PROGRAD, COPERVES, CAL, 1998

NUNAN, David. Designing Tasks for the Communicative Classroom. Cambridge University Press,1989.

RICHTER, Marcos Gustavo. Ensino do Português e Interatividade. Santa Maria: Ed. da UFSM, 2000

WALLACE, Catherine. Critical Literacy Awareness in the EFL Classroom. In: N. Fairclough. Critical Language Awareness. Longman,1996 